\title{
Fourier Transform Infrared Spectral Analysis of Polyisoprene of a Different Microstructure
}

\author{
Dongmei Chen, ${ }^{1}$ Huafeng Shao, ${ }^{2}$ Wei Yao, ${ }^{2}$ and Baochen Huang ${ }^{2}$ \\ ${ }^{1}$ High Performance Polymer Institute of Qingdao University of Science and Technology, Qingdao 266042, China \\ ${ }^{2}$ Key Lab of Rubber and Plastic, Ministry of Education, Qingdao University of Science and Technology, Qingdao 266042, China
}

Correspondence should be addressed to Dongmei Chen; cdm321@126.com

Received 4 April 2013; Accepted 22 May 2013

Academic Editor: Zhou Yang

Copyright (c) 2013 Dongmei Chen et al. This is an open access article distributed under the Creative Commons Attribution License, which permits unrestricted use, distribution, and reproduction in any medium, provided the original work is properly cited.

\begin{abstract}
Some polyisoprene samples of different microstructure contents were studied by Fourier transform infrared (FTIR) and ${ }^{1} \mathrm{H}$ Nuclear magnetic resonance $\left({ }^{1} \mathrm{H}\right.$ NMR). On the basis of detailed analysis of FTIR spectra of polyisoprene, the shift of absorption peaks caused by microstructure content's variation was discussed. The contents of the polyisoprene samples' microstructure which was determined by the ${ }^{1} \mathrm{H}$ NMR was used as the standard. Through the choice, calculation, and comparison with the corresponding absorption peaks of FTIR, a method based on the results of the analysis has been developed for the determination of the microstructure contents of polyisoprene by FTIR.
\end{abstract}

\section{Introduction}

As it is well known, polyisoprene (PIp) is one kind of important rubbers, and there are four kinds of microstructure in its molecular chain which are cis-1,4-, trans-1,4-, 1,2-, and 3,4polyisoprene. The main ingredient of nature rubber is cis-1,4or trans-1,4-polyisoprene. For example, Hevea brasiliensis (the Brazilian rubber tree) is polyisoprene with more than 5,000 cis-1,4-repeat units except for the transinitiator residue of repeat units ranging from 1 to 4 , depending on the plant species. Gutta-percha, Balata, or Malaysian rubber is polyisoprene with trans-1,4-repeat units [1-4]. Since English chemist Michael Faraday found that the structure unit of nature rubber was $\mathrm{C}_{5} \mathrm{H}_{8}$, the research of synthetic polyisoprene keeps active [1-7].

Except for the synthesis of high content of cis-1,4- or trans-1,4-polyisoprene to imitate and replace nature rubber, the research on synthesis of polyisoprene with variable microstructure contents keeps attractive in order to obtain some materials of special properties. For example, with 3,4unit content's increasing, the curing rate and low temperature properties of polyisoprene decrease, but hardness and elasticity increase, as well as tensile properties, tension set, and tearing strength maintain are slightly changed. Particularly, the water resistance and hermeticity of polyisoprene with high 3,4-unit content can compare with butyl rubber [8-11]. The application of polyisoprene with high 3,4-unit content in tread can improve the skidding resistance, traction property, and cutting growing resistance and also can decrease the generation of heat by friction So it is the new varieties of rubber for a fuel-saving, environmental protection and safety tire.

Most of the studies on microstructure of polymers are characterized by nuclear magnetic resonance (NMR) spectrophotometer and FTIR [12, 13]. The first extensive IR spectroscopic studies of synthetic polyisoprenes were undertaken by Binder, Cornell, and Koenig. In comparison with other polymers, much less work has been reported on polyisoprene [14]. In this paper, polyisoprenes of some different microstructure content are analyzed by FTIR in details. Through comparison the intensity of corresponding microstructure characterization peak in FTIR with in NMR, the experience relation equation is founded and the method of calculating the microstructure content of polyisoprene by FTIR is also established. 


\section{Experimental}

2.1. Materials. All the polyisoprene samples with variable microstructure content were polymerized according to [15$18]$.

\subsection{Characterization}

2.2.1. FTIR. Tensor 27 (Bruker, German) has been used in the analysis. The samples are tested by ATR-FTIR, with $4 \mathrm{~cm}^{-1}$ resolution, and scanned 32 times.

2.2.2. ${ }^{1}$ H NMR. AV500 (Bruker, German) has been used in the analysis. ${ }^{1} \mathrm{H}$ NMR spectra of the polyisoprene in $\mathrm{CDCl}_{3}$ were obtained at $500.13 \mathrm{~Hz}$, and chemical shifts were referred to TMS

The ${ }^{1} \mathrm{H}$ NMR spectrum of polyisoprene which contains $1,4-, 1,2-$, and 3,4-unit is shown in Figure 1. $85.2 \sim 5.0, \delta 5.0 \sim 4.8$, and $\delta 4.8 \sim 4.6$ peaks are ascribed to the olefinic hydrogen of 1,4-, 1,2-, and 3,4-unit, respectively. Determining the intensity of these spectral lines, then calculating 1,4-, 1,2-, and 3,4-unit content with formula (1), and the results are shown in Table 1:

$$
\begin{aligned}
& X_{1,4 \text {-PIp }} \\
& =\frac{\int \delta 5.2-5.0}{\int \delta 5.2-5.0+\left(\int \delta 5.0-4.8+\int \delta 4.8-4.6\right) / 2} \times 100 \%, \\
& X_{1,2 \text {-PIp }} \\
& =\frac{\int \delta 5.0-4.8 / 2}{\int \delta 5.2-5.0+\left(\int \delta 5.0-4.8+\int \delta 4.8-4.6\right) / 2} \times 100 \%, \\
& X_{3,4-\operatorname{PIp}} \frac{\int \delta 4.8-4.6 / 2}{\int \delta 5.2-5.0+\left(\int \delta 5.0-4.8+\int \delta 4.8-4.6\right) / 2} \times 100 \% .
\end{aligned}
$$

\section{Results and Discussion}

3.1. Analysis of FTIR Spectra of Polyisoprene. Polyisoprene has four kinds of microstructure which are cis-1, 4-, trans-1, 4-, 1, 2-, and 3, 4-polyisoprene, as shown in Figure 2.

Figure 3 shows seven FTIR spectra of polyisoprene with different microstructure content.

The characterization and attribution peaks of FTIR spectra of polyisoprene are listed in Table 2.

It can be seen from Figure 3 and Table 2 that the difference of FTIR behavior of the polyisoprene microstructures is obvious. However, only 910,888 , and $840 \mathrm{~cm}^{-1}$ peaks can be used for quantitative calculation of microstructure content of polyisoprene. It is because that the peaks for quantitatively calculation must have moderate intensity, little interfering factors by other peaks or conditions, and so on. Except for those differences shown in Table 2, Table 3 shows some frequency excursion caused by microstructure content changing.

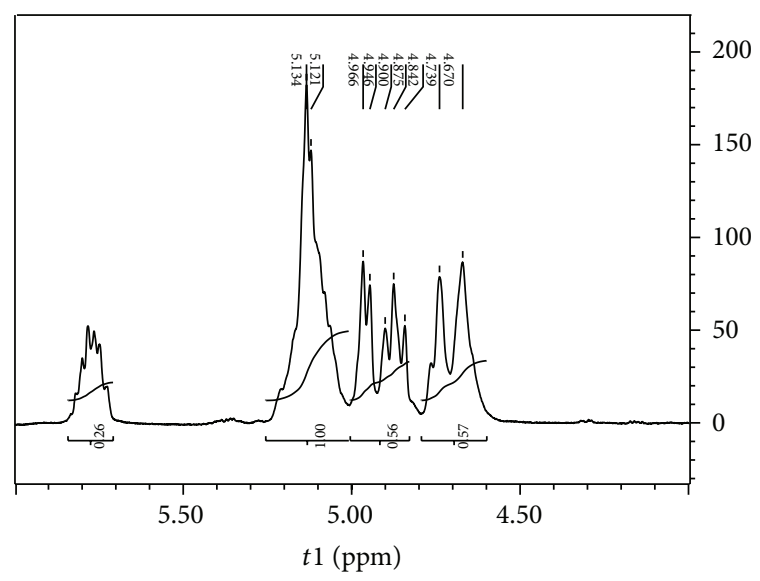

FIgURE 1: ${ }^{1} \mathrm{H}$ NMR spectrum of polyisoprene.

TABLE 1: Microstructure contents of polyisoprene by ${ }^{1} \mathrm{H}$ NMR.

\begin{tabular}{lccc}
\hline Sample & $1,4-\mathrm{mol} \%$ & 3,4 -mol\% & $1,2-\mathrm{mol} \%$ \\
\hline A & $100($ cis-1,4) & 0 & 0 \\
\hline B & $99.6($ trans-1,4) & 0.2 & 0.2 \\
\hline C & 90 & 5 & 5 \\
D & 53 & 24 & 23 \\
E & 30 & 59 & 11 \\
F & 24 & 63 & 13 \\
G & 18 & 67 & 15 \\
\hline
\end{tabular}

\subsection{Quantization Calculation of Microstructure Content of} Polyisoprene by FTIR. According to the Beer-Lambert law, the integrated intensity $A$ of a characteristic band can be expressed as follows:

$$
A=b c \int_{0}^{+\infty} \varepsilon(\nu) d_{\nu}
$$

Here, $\varepsilon$ is the absorption coefficient, $b$ is the thickness, $c$ is the concentration, and $v$ is the wavenumber.

Choosing a peak which has moderate intensity and is not affected by configuration, conformation or other structure factors as internal standard of thickness, then formula (2) can be changed to the following:

$$
[A]=\frac{A_{1}}{A_{0}}=c_{1}\left[\frac{\int_{0}^{+\infty} \varepsilon\left(\vartheta_{1}\right) d_{\vartheta}}{c_{0} \int_{0}^{+\infty} \varepsilon\left(\vartheta_{0}\right) d_{\vartheta}}\right]=c_{1} \cdot k .
$$

Here, "1" means characteristic band and " 0 " means internal standard band. " $K$ " is the correction factor and can be calculated by ${ }^{1} \mathrm{H}$ NMR dates. As described above, 910, 888, and $840 \mathrm{~cm}^{-1}$ peaks can be used for quantitatively calculating microstructure content of polyisoprene. Table 2 shows that there is seldom peak which can meet the request of internal standard peak. In this paper, $2727 \mathrm{~cm}^{-1}$ is used as internal standard peak. The integrated intensity $A$ are calculated by the software of FTIR, and the integration methods are shown in Figure 4. 


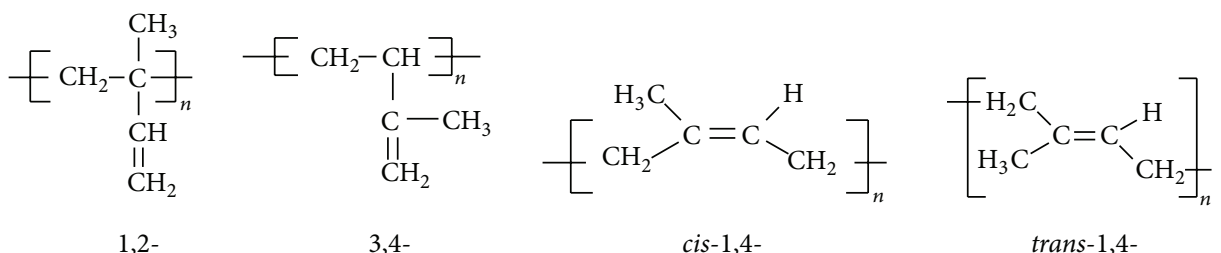

FIGURE 2: The structural formula of polyisoprene.

TABLE 2: The explanation of absorption peaks of FTIR spectrum of polyisoprene.

\begin{tabular}{|c|c|c|c|}
\hline Wavenumber $/ \mathrm{cm}^{-1}$ & Attribution & Wavenumber $/ \mathrm{cm}^{-1}$ & Attribution \\
\hline 3080 & $\begin{array}{c}\text {-C-H stretching vibration of } \\
\text { carbon-carbon double bond in } \\
1,2 \text {-unit }\end{array}$ & 1150 & $\begin{array}{l}\text { Stretching vibration of CC main } \\
\text { chain in trans-1,4-unit }\end{array}$ \\
\hline 3070 & $\begin{array}{c}\mathrm{CH}_{2} \text { stretching vibration of } \\
-\mathrm{C}=\mathrm{C}-\text { in 3,4-unit }\end{array}$ & 1140 & $\begin{array}{l}\text { Stretching vibration of CC main } \\
\text { chain in cis-1,4-unit }\end{array}$ \\
\hline 3035 & $\begin{array}{l}\text { CH stretching vibration of } \\
-\mathrm{C}=\mathrm{C}-\text { in } 1,4-\text { or } 1,2 \text {-unit }\end{array}$ & 1044 & $\begin{array}{l}\text { Stretching or wagging vibration } \\
\text { of } \mathrm{CH}_{3} \mathrm{C}=\mathrm{C} \text { in trans-1,4-unit }\end{array}$ \\
\hline 2727 & Sympathetic vibration & 1036 & $\begin{array}{l}\text { Stretching or wagging vibration } \\
\text { of } \mathrm{CH}_{3} \mathrm{C}=\mathrm{C} \text { in } c i s-1,4 \text {-unit }\end{array}$ \\
\hline 1663 & $\begin{array}{c}\mathrm{C}=\mathrm{C} \text { stretching vibration of } \\
\text { 1,4-unit }\end{array}$ & 1003 & $\begin{array}{c}\text { Stretching vibration of } \mathrm{C}-\mathrm{C} \text { in } \\
\text { 3,4-unit }\end{array}$ \\
\hline 1644 & $\begin{array}{c}\mathrm{C}=\mathrm{C} \text { stretching vibration of } \\
3,4-\text { or } 1,2 \text {-unit }\end{array}$ & 910 & $\begin{array}{l}\text { Out-of-plane bending vibration } \\
\text { of } \mathrm{CH}_{2} \text { in the }-\mathrm{CH}=\mathrm{CH}_{2} \\
(1,2 \text {-unit })\end{array}$ \\
\hline 1413 & $\begin{array}{c}\text { Bending vibration of } \mathrm{C}-\mathrm{H} \text { in } \\
\text { the }=\mathrm{CH}_{2} \text { group of } 3,4-\text { or } \\
\text { 1,2-unit }\end{array}$ & 888 & $\begin{array}{l}\text { Out-of-plane bending vibration } \\
\text { of } \mathrm{CH}_{2} \text { in the }-\mathrm{C}=\mathrm{CH}_{2} \text { (3,4-unit) }\end{array}$ \\
\hline 1383 & $\begin{array}{l}\text { Scissoring vibration of } \mathrm{CH}_{3} \text { in } \\
\text { trans-1,4-unit }\end{array}$ & 843 & $\begin{array}{l}\text { Out-of-plane bending vibration } \\
\text { of } \mathrm{C}-\mathrm{H} \text { in the }-\mathrm{CH}=\mathrm{CH} \text { - group } \\
\text { of trans-1,4-unit }\end{array}$ \\
\hline 1375 & $\begin{array}{l}\text { Scissoring vibration of } \mathrm{CH}_{3} \text { in } \\
\text { cis-1,4-, 3,4- and 1,2-units }\end{array}$ & 837 & $\begin{array}{l}\text { Out-of-plane bending vibration } \\
\text { of } \mathrm{C}-\mathrm{H} \text { in the }-\mathrm{CH}=\mathrm{CH} \text { - group } \\
\text { of } c i s-1,4 \text {-unit }\end{array}$ \\
\hline 1325 & $\begin{array}{c}\text { Scissoring vibration of } \mathrm{CH}_{3} \text { or } \\
\mathrm{CH} \text { in trans-1,4-unit }\end{array}$ & 600 & $\begin{array}{l}\text { Torsion or twisting vibration of } \\
\text { CCC group in trans-1,4-unit }\end{array}$ \\
\hline 1311 & $\begin{array}{l}\text { Scissoring vibration of } \mathrm{CH}_{3} \text { or } \\
\mathrm{CH} \text { in cis-1,4-unit }\end{array}$ & & \\
\hline
\end{tabular}

TABLE 3: The change of peaks of FTIR spectra according to the microstructure contents of polyisoprene.

\begin{tabular}{|c|c|c|c|c|}
\hline Explanation $\backslash$ peak value & Spectrum A & Spectrum B & Spectrum C & Note \\
\hline \multicolumn{5}{|l|}{ Microstructure content } \\
\hline 3,4-unit $\%$ & 5 & 24 & 67 & 3,4-unit $\%$ increase by progressively \\
\hline 1,2 -unit $\%$ & 5 & 23 & 15 & 1,2-unit\% increase by degrees \\
\hline 1,4 -unit $\%$ & 90 & 53 & 18 & 1,4-unit $\%$ decrease by degrees \\
\hline $\begin{array}{l}\text { Dissymmetry stretching vibration } \\
\text { of }-\mathrm{CH}_{3}\end{array}$ & 2962.125 & 2964.053 & 2965.982 & $\begin{array}{c}\text { Blue shift of peak (the value is } 2978 \mathrm{~cm}^{-1} \text { in } \\
\text { trans-1,4-unit) }\end{array}$ \\
\hline $\mathrm{C}=\mathrm{C}$ stretching vibration & 1644.982 & 1644.018 & 1643.054 & Red shift of peak \\
\hline Scissoring vibration of $\mathrm{CH}_{3}$ & 1376.925 & 1374.997 & 1374.033 & $\begin{array}{c}\text { Red shift of peak (the value is } 1383 \mathrm{~cm}^{-1} \text { in } \\
\text { trans-1,4-unit) }\end{array}$ \\
\hline $\begin{array}{l}\text { Out-of-plane bending vibration of } \\
\mathrm{CH}_{2} \text { in the }-\mathrm{C}=\mathrm{CH}_{2} \text { (3,4-unit) }\end{array}$ & 889.023 & 888.059 & 887.095 & Red shift of peak \\
\hline $\begin{array}{l}\text { Out-of-plane bending vibration of } \\
\mathrm{C}-\mathrm{H} \text { in the }-\mathrm{CH}=\mathrm{CH} \text { - group of } \\
\text { 1,4-unit }\end{array}$ & 836.955 & 840.812 & $\begin{array}{l}848.849 \\
\text { (flat top) }\end{array}$ & blue shift of peak \\
\hline
\end{tabular}




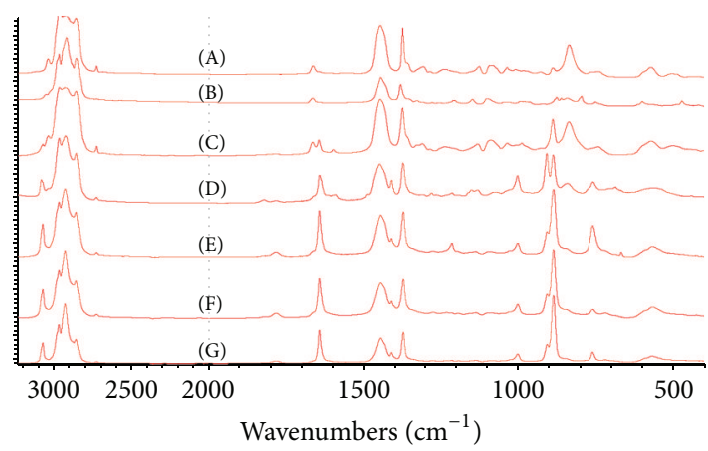

FIGURE 3: FTIR spectra of polyisoprenes of variable microstructure content. (A) cis-1,4- = 100\% 3,4- = 0\% 1,2- = 0\%; (B) trans-1,4- = 99.6\% 3,4- = 0.2\% 1,2- = 0.2\%; (C) 1,4- = 90\% 3,4- = 5\% 1,2- = 5\%; (D) $1,4-=53 \% 3,4-=24 \% 1,2-=23 \%$; (E) $1,4-=30 \% 3,4-=59 \% 1,2-$ $=11 \%$; (F) $1,4-=24 \% 3,4-=63 \% 1,2-=13 \%$; (G) $1,4-=18 \% 3,4-=67 \%$ $1,2-=15 \%$.

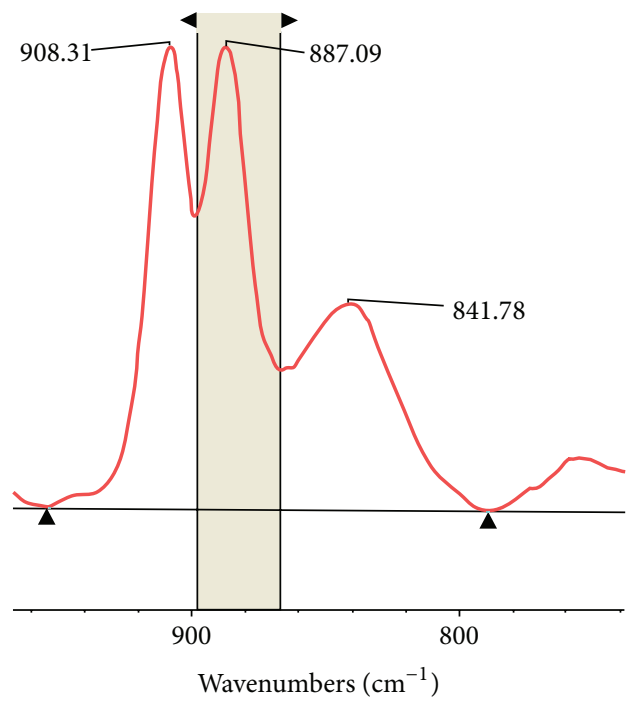

(a)

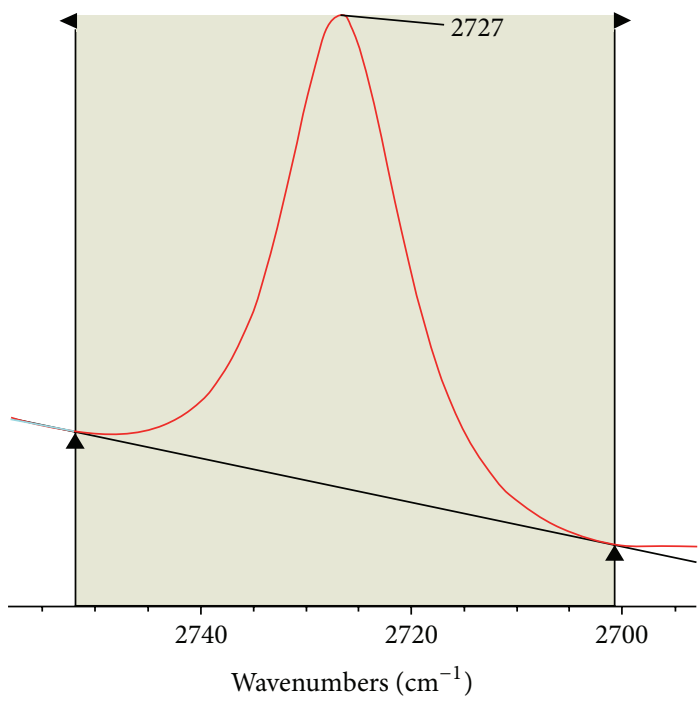

(b)

FIGURE 4: Samples of absorption values of peaks of polyisoprene.

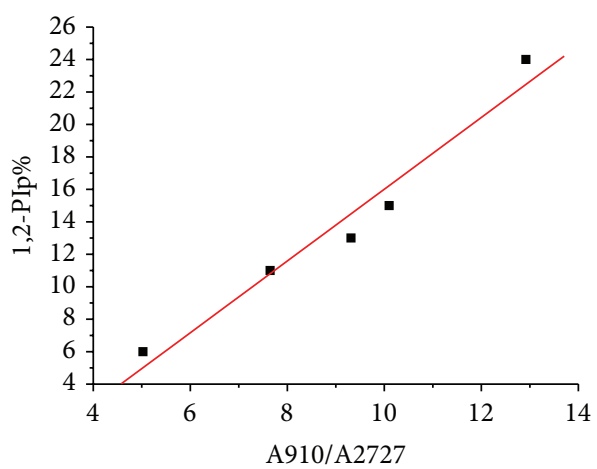

(a)

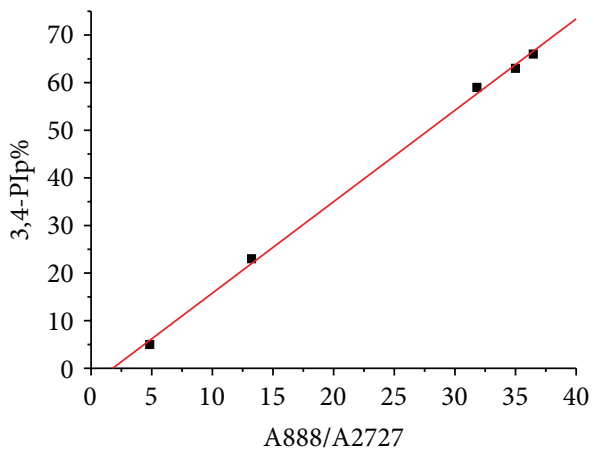

(b)

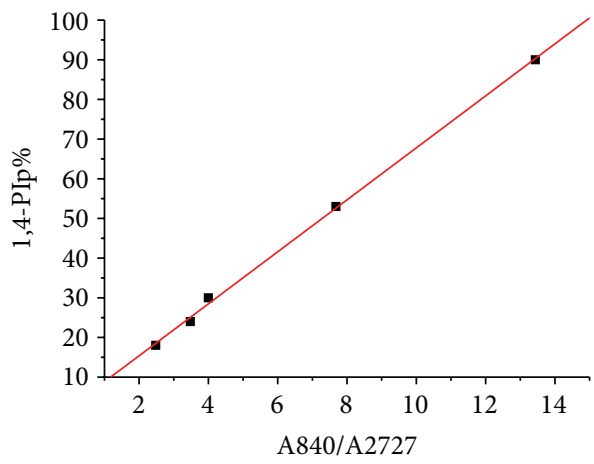

(c)

FIGURE 5: The absorption coefficient calculation of (a) $910 \mathrm{~cm}^{-1}$, (b) $888 \mathrm{~cm}^{-1}$, and (c) $840 \mathrm{~cm}^{-1}$ peaks of FTIR spectra of polyisoprene.

The samples shown in Table 1 are calculated with this method, and the results are given in Figure 5.

After regression of measured points of testing points based on a least-squares method, the formula of microstructure content is shown as follows:

$$
\begin{aligned}
& X_{1,2-\mathrm{PIp}}=2.21[A]_{910 \mathrm{~cm}^{-1}}-6.10, \\
& X_{3,4-\mathrm{PIp}}=1.92[A]_{888 \mathrm{~cm}^{-1}}-3.40, \\
& X_{1,4-\mathrm{PIP}}=6.55[A]_{840 \mathrm{~cm}^{-1}}+2.29 .
\end{aligned}
$$

Because of 910,888 , and $840 \mathrm{~cm}^{-1}$ peak overlaps partly, the errors of calculated values of integrated intensity $A$ will increase when the peak's intensity is too small. Therefore, the 
microstructure content shall be calculated with two higher peaks. In the 1,2- and 3,4-unit, the double bond is on the branched chain and belongs to asymmetry substitute, so their dipole moment's shift is bigger than that of 1,4-unit. As a result, the integrated intensity of 910 and $888 \mathrm{~cm}^{-1}$ peak is far stronger than $840 \mathrm{~cm}^{-1}$ peak when the contents of their corresponding units are the same. Therefore, the calculation of microstructure content of polyisoprene shall choose the former two peaks.

\section{Conclusion}

The change of microstructure content of polyisoprene can cause a lot of differences in FTIR spectra. The described method by FTIR can be used to determine the microstructure content of polyisoprene. 910 and $888 \mathrm{~cm}^{-1}$ peaks of $1,2-$ or 3,4-unit have higher absorption ability than $840 \mathrm{~cm}^{-1}$ peaks of 1,4-unit; therefore 910 and $888 \mathrm{~cm}^{-1}$ peaks shall be used first for the quantitative analysis of microstructure content of polyisoprene. The quantitative calculation formulas were also obtained.

\section{References}

[1] J. E. Puskas, F. Peruch, A. Deffieux et al., "Biomimetic carbocationic polymerizations III: Investigation of isoprene polymerization initiated by dimethyl allyl bromide," Journal of Polymer Science Part A, vol. 47, no. 8, pp. 2172-2180, 2009.

[2] J. E. Puskas, C. Peres, F. Peruch et al., "Biomimetic processes. IV. carbocationic polymerization of isoprene initiated by dimethyl allyl alcohol," Journal of Polymer Science Part A, vol. 47, no. 8, pp. 2181-2189, 2009.

[3] A. Avgeropoulos, S. Paraskeva, N. Hadjichristidis, and E. L. Thomas, "Synthesis and microphase separation of linear triblock terpolymers of polystyrene, high 1,4-polybutadiene, and high 3,4-polyisoprene," Macromolecules, vol. 35, no. 10, pp. 4030-4035, 2002.

[4] B. Wang, D. Wang, D. Cui et al., "Synthesis of the first rare earth metal bis(alkyl)s bearing an indenyl functionalized Nheterocyclic carbene," Organometallics, vol. 26, no. 13, pp. 31673172, 2007.

[5] G. Ricci, M. Battistella, and L. Porri, "Chemoselectivity and stereospecificity of chromium(II) catalysts for 1,3-diene polymerization," Macromolecules, vol. 34, no. 17, pp. 5766-5769, 2001.

[6] G. Ricci, D. Morganti, A. Sommazzi, R. Santi, and F. Masi, "Polymerization of 1,3-dienes with iron complexes based catalysts influence of the ligand on catalyst activity and stereospecificity," Journal of Molecular Catalysis A, vol. 204-205, pp. 287-293, 2003.

[7] C. Bazzini, A. Giarrusso, L. Porri, B. Pirozzi, and R. Napolitano, "Synthesis and characterization of syndiotactic 3,4polyisoprene prepared with diethylbis $\left(2,2^{\prime}\right.$-bipyridine $)$ ironMAO," Polymer, vol. 45, no. 9, pp. 2871-2875, 2004.

[8] T. Yu, B. Huang, W. Yao et al., "Research and development of 3,4-polyisoprene rubber," China Synthetic Rubber Industry, vol. 27, no. 2, pp. 122-126, 2004.

[9] W. Zhang, B. Huang, A. Du et al., "Properties of TPI/HVBR/NR blends," China Rubber Industry, vol. 49, no. 1, pp. 5-8, 2002.
[10] W. Zhang, B. Huang, A. Du et al., "Properties of TPI/HVBR/ SBR blends," China Rubber Industry, vol. 49, no. 2, pp. 69-72, 2002.

[11] Z. Zhao, "The applied technology and properties of polyisoprene of high 3,4-isomer content," China Rubber Collection of Translations, no. 2, pp. 66-69, 1996.

[12] B. Huang, W. Zhang, A. Du et al., "Application of TPI/HVBR blend to tread," China Rubber Industry, vol. 49, no. 3, pp. 133137, 2002.

[13] D. Derouet, S. Forgeard, J.-C. Brosse, J. Emery, and J.-Y. Buzare, "Application of solid-state NMR (13C and29Si CP/MAS NMR) spectroscopy to the characterization of alkenyltrialkoxysilane and trialkoxysilyl-terminated polyisoprene grafting onto silica microparticles," Journal of Polymer Science Part A, vol. 36, no. 3, pp. 437-453, 1998.

[14] V. Arjunan, S. Subramanian, and S. Mohan, "Fourier transform infrared and Raman spectral analysis of trans-1,4-polyisoprene," Spectrochimica Acta Part A, vol. 57, no. 13, pp. 2547-2554, 2001.

[15] B. Huang, J. He, J. Song et al., "New polymerization method of high trans1, 4-polyisoprene," CN1048257C, China, January 2000.

[16] B. Huang, Z. Zhao, W. Yao et al., "Industrial production method of high trans1,4-polyisoprene," CN1847272A, China, October 2006.

[17] P. Wang, H. Shao, W. Yao et al., "Polymerization of isoprene initiated with tetra-n-butyl titanate supported titanium catalyst and triethylaluminium," China Synthetic Rubber Industry, vol. 32, pp. 284-284, 2009.

[18] R. Gao, T. Yu, L. Bi et al., "Research on novel Mg-Ti-Al complex and its catalysis for olefin polymerization," China Synthetic Resin and Plastics, vol. 24, no. 6, pp. 25-28, 2007. 

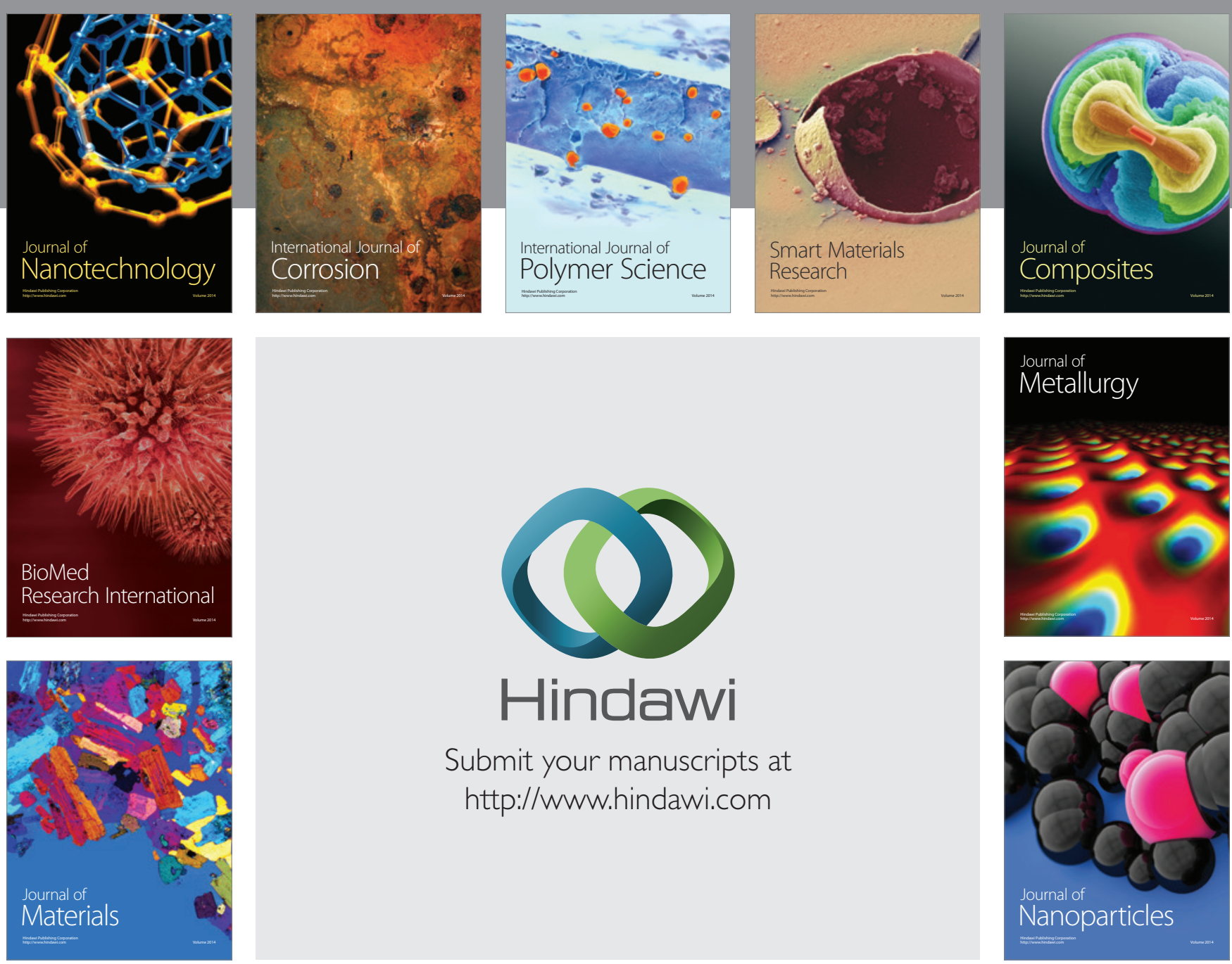

Submit your manuscripts at http://www.hindawi.com
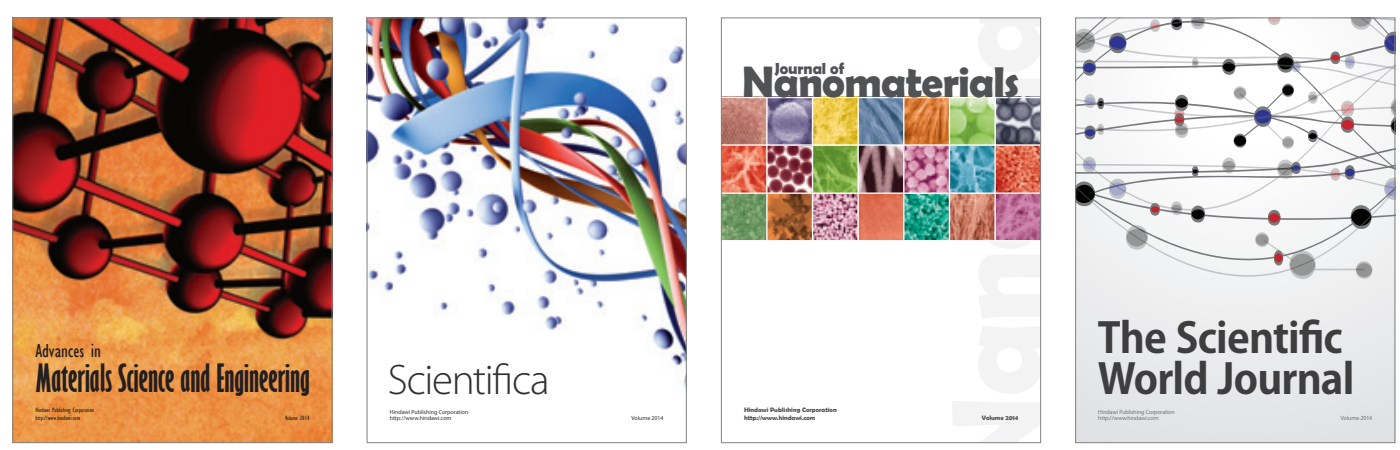

\section{The Scientific World Journal}
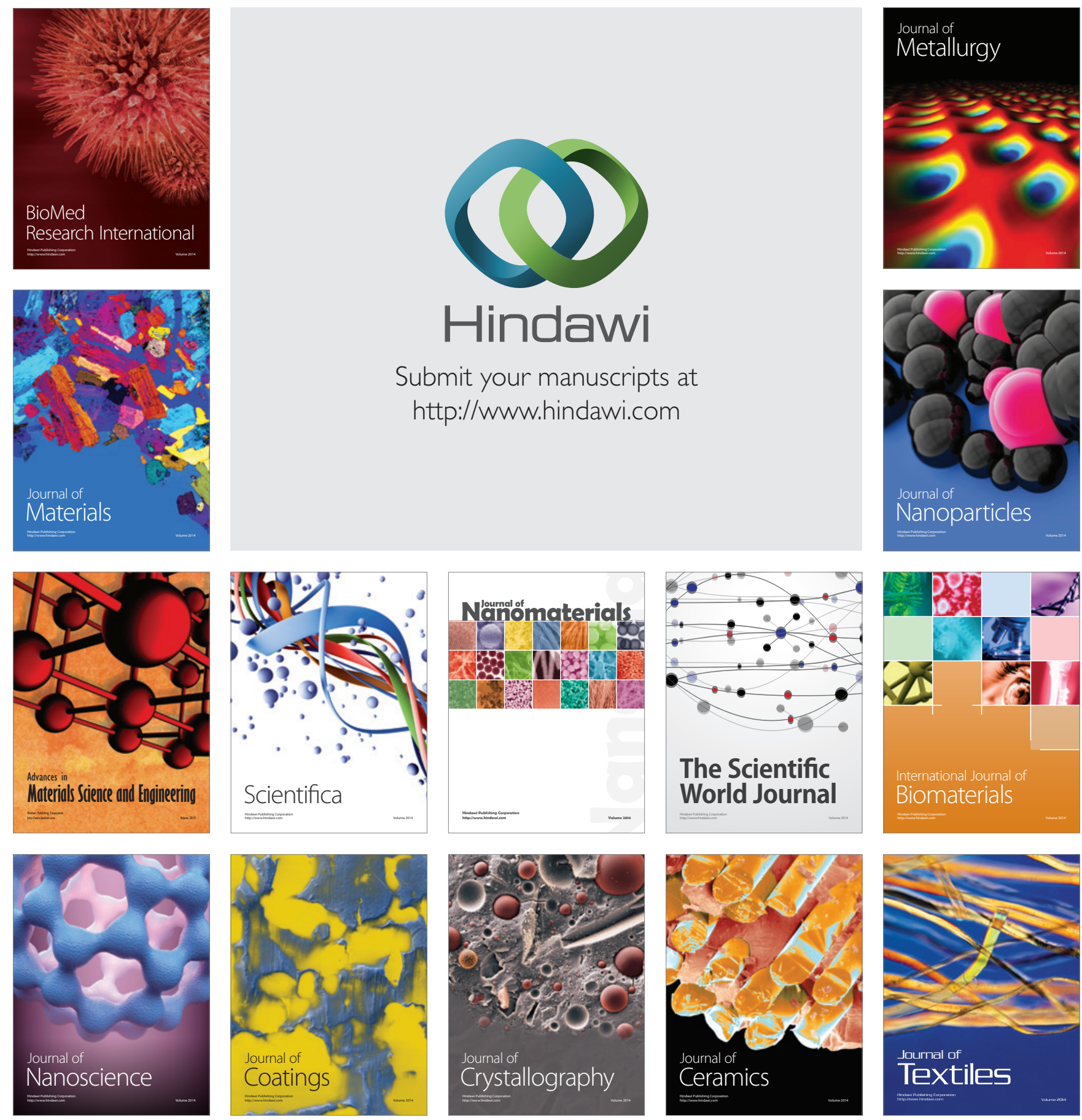